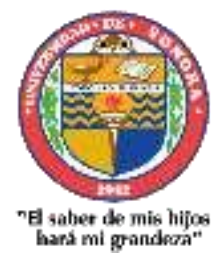

(Julio - Diciembre 2020)

Año 13.

Núm. 33
Revista de Investigación Académica sin Frontera

ISSN: 2007-8870

Recibido el 3 de julio de 2020. Dictaminado mediante arbitraje favorablemente 9 de noviembre de 2020.

\title{
Actividad física en ambientes laborales virtuales para la salud fisica y psicologica del trabajador
}

\author{
MAPE. María Julia León Bazán \\ julia.leon@unison.mx \\ ORCID: 0000-0002-7405-6141 \\ Universidad de Sonora, Unidad Centro \\ Dra. María Lizett Zolano Sánchez \\ maria.zolano@unison.mx \\ ORCID: 0000-0001-7526-2038 \\ Universidad de Sonora, Unidad Centro
}

\begin{abstract}
RESUMEN
Este trabajo de investigación se realizó bajo un enfoque metodológico descriptivo y exploratorio, tomando como referencia las Pequeñas y medianas empresas (Pymes) del sector comercio minorista, con una antigüedad de cinco años en el mercado, ubicadas en Hermosillo, Sonora, México y que están en confinamiento debido a COVID-19. El objetivo es describir los efectos derivados del trabajo reorganizado a través del teletrabajo a partir del COVID-19, sobre la calidad de vida laboral percibida por un grupo de trabajadores de las Pymes y, determinar como la actividad física influye en la mejora de la salud psicológica que ayuda en el rendimiento del trabajador durante la pandemia. Se aplicó un cuestionario estandarizado donde se analizaron dos variables: Variable 1; Calidad de vida laboral durante el Teletrabajo a partir del COVID-19 y Variable 2; Actividad Física y Salud. Los principales resultados muestran en la variable 1, que los trabajadores no estan acostumbrados a trabajar desde casa, no cuentan con los medios ni la preparación técnica para hacerlo. En la variable 2, el confinamiento les ha llevado a aislarse de la familia y los amigos porque invierten muchas horas de trabajo continuo y descuidan sus habitos alimenticios, lo que les ha provocado cansancio que aunado a la falta de actividad física les genera estrés y ansiedad, poniendo en riesgo su salud física y mental. Como conclusión final, la realización de actividad física, puede ayudar a mejorar la salud psicológica del individuo de tal forma que podría reflejarse en su desempeño laboral.
\end{abstract}

Palabras Clave: Actividad Fisica, Calidad de Vida Laboral, COVID-19, Pymes, Salud. 


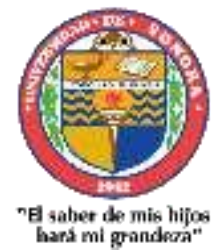

Año 13.

Núm. 33
Revista de Investigación Académica sin Frontera ISSN: 2007-8870 https://revistainvestigacionacademicasinfrontera.unison.mx/index.php/RDIASF

Recibido el 3 de julio de 2020. Dictaminado mediante arbitraje favorablemente 9 de noviembre de 2020.

\title{
Physical activity in virtual work environments for the physical and psychological health of the worker
}

\begin{abstract}
This research work was carried out under a descriptive and exploratory methodological approach, taking reference to Small and medium-sized enterprises (SMEs) retail comerce sector, with an antiquity of five years in the market, located in Hermosillo, Sonora, Mexico and and who are in confinement due to COVID-19. The objective is to describe the effects derived from reorganized work through telework starting COVID-19, on the quality of working life perceived by a group of workers of SMEs and, to determine how physical activity influences to improve psychological health that helps in worker performance during the pandemic. A standardized questionnaire was applied where two variables were analyzed: Variable 1; Quality of work life during Telework due to COVID-19 and Variable 2; Physical activity and health. The main results show in variable 1, that workers are not used to working from home, they do not have the means or the technical preparation to do so. In variable 2, confinement has led them to isolate themselves from family and friends because they invest many hours of continuous work and neglect their eating habits, which has caused them fatigue that, together with the lack of physical activity, generates stress and anxiety , puting your physical and mental health in risk. As a final conclusion, doing physical activity can help improve the psychological health of the individual in such a way that it could be reflected in their work performance.
\end{abstract}

Key words: Physical Activity, Quality of Work Life, COVID-19, SMEs, Health.

\section{Introducción}

De acuerdo con la Organización Internacional del Trabajo- OIT (2017), el teletrabajo consiste en utilizar la disponibilidad de la telecomunicación y las herramientas facilitadoras (TIC's) como medidas de innovación, a fines de efectuar el trabajo a distancia desde cualquier lugar. Una modalidad del teletrabajo consiste en el HO (Home Office) y, según Saco (2007), se refiere a la modalidad más pura del teletrabajo mediante el cual el teletrabajador realiza sus actividades desde su domicilio de manera permanente o distribuida, entre empresa y domicilio. 
Recibido el 3 de julio de 2020. Dictaminado mediante arbitraje favorablemente 9 de noviembre de 2020.

En base a diferentes escenarios sobre las consecuencias del COVID-19 en el crecimiento del PIB mundial, las estimaciones de la OIT indican un aumento del desempleo mundial de entre 5,3 millones y 24,7 millones de personas (OIT, 2020). Los gobiernos han realizado esfuerzos para generar estrategias para reactivar la economía de sus países con el reimpulso de uso de plataformas tecnológicas y comercio electrónico, pero al parecer este trabajo ha sido insuficiente para aumentar los niveles de eficiencia de los mercados y reactivar medianamente el aparato productivo (Díaz y Ramos, 2019).

La acción de los gobiernos ha sido el reflejo de ensayo y error en las decisiones y, el caso actual de México no es la excepción ya que las pandemias, a lo largo de la historia han creado en nuestro país desempleo problemas en la calidad de vida de los trabajadores a partir de la incertidumbre y la desaceleración económica, donde la mayoría de sus empresas son pequeñas y, por otro lado, existe una alta tasa de informalidad laboral por la falta de aprovechamiento del capital humano (Sánchez y Hernández, 2020). La situación actual provocada por el COVID-19, ha hecho que todos los trabajadores realicen su trabajo desde casa, por lo que la empresa debe considerar como una estrategia de gestión empresarial, la mejora de la calidad de vida del trabajador porque es parte integral del desarrollo personal, y deben considerarse dentro del marco de políticas empresariales que son contenidas para el logro de un clima organizacional efectivo, de tal forma que sean tomados en cuenta todos aquellos aspectos que afecten su comportamiento, como en el caso del desempeño laboral, las áreas de trabajo, y la gestión empresarial dentro del clima organizacional (Grote y Guest, 2017; Culma, Londoño, García, y Tabares, 2020).

La actividad física y su incidencia en el mejoramiento de la calidad de vida del hombre, desde el punto de vista de su salud y el desarrollo psicosocial, constituyen uno de los temas de estudio más importantes en la actualidad, no únicamente por expertos en temas de la cultura física y los deportes, sino también por médicos, especialistas en psicología, profesores de la especialidad, 


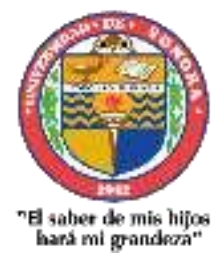

Año 13.

Núm. 33

Revista de Investigación Académica sin Frontera ISSN: 2007-8870 https://revistainvestigacionacademicasinfrontera.unison.mx/index.php/RDIASF

Recibido el 3 de julio de 2020. Dictaminado mediante arbitraje favorablemente 9 de noviembre de 2020. gobierno, sector empresarial y la población de forma general coinciden en la necesidad de incorporar a la cultura y la educación, aquellos conocimientos, destrezas y capacidades que relacionadas con el cuerpo y su actividad motriz, contribuyen al desarrollo personal del individuo y a una mejor calidad de vida (Sobrado, 2008; de Miguel, Schweiger, de las Mozas y Hernández, 2011; Meza, 2017). Es necesario que el individuo pueda compaginar su vida con el teletrabajo, porque la Actividad Física incide positivamente en la condición física del individuo sano o con problemas psicomotrices (Sandoval, Marcel y Carrasco, 2015; Sandoval y Burbano, 2015), en la disminución del sedentarismo (Montero y Chávez, 2015; Morales, Velasco, Lorenzo, Torres y Enríquez, 2016), el estado de ánimo y las conductas sociales (Mencías, Ortega, Zuleta y Calero, 2016; Morales, Cumbajin, Torres y Analuiza, 2016), entre otros.

Para que la actividad física repercuta benéficamente en la salud es necesario ponerla en práctica por un determinado tiempo y frecuencia. De acuerdo a las recomendaciones de la Organización Mundial de la Salud (OMS, 2018), para adultos de 18 a 65 años se recomienda ejercicio aeróbico de intensidad moderada durante 30 minutos, 5 veces a la semana o 150 minutos semanales y si ya realizan ejercicio aeróbico de alta intensidad, se recomiendan períodos de 20 minutos, 3 veces a la semana.

Las medidas implementadas a partir de la pandemia provocada por el COVID-19, relacionada con la restricción de la participación en actividades al aire libre, así como los desplazamientos a escuelas, universidades y sitios de trabajo, reducen el tiempo dedicado a la realización de Actividad física y Ejercicio (Chen, Mao, Nassis, Harmer, Ainsworth y Li, 2020), que previo a la emergencia sanitaria ya era considerado como problema de salud pública mundial grave (Lee et al., 2012), favoreciendo la aparición probleméticas asociados a la inactividad física, tales como el sedentarismo, el incremento en el consumo de alimentos con alto aporte calórico, bebidas 


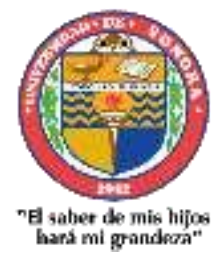

Año 13.

Núm. 33

(Julio - Diciembre 2020)

Revista de Investigación Académica sin Frontera ISSN: 2007-8870 https://revistainvestigacionacademicasinfrontera.unison.mx/index.php/RDIASF

Recibido el 3 de julio de 2020. Dictaminado mediante arbitraje favorablemente 9 de noviembre de 2020.

alcohólicas, la mala calidad del sueño (Gené, Ruiz, Obiols, Oliveras y Lagarda, 2016; Chen et al., 2020), condiciones que en conjunto favorecen el desacondicionamiento físico.

La pandemia de COVID-19 ha llevado a muchos trabajadores a quedarse en casa, mantener menos interacciones sociales y hacer menos ejercicio, provocando con ello consecuencias negativas para la salud física y mental, por lo que generar hábitos relacionados con la práctica de actividad física en casa, realizarla de manera programada, establecer horarios de descanso entre las actividades y durante la noche, y elegir aquellas que generen disfrute (Mera, Tabares, Montoya, Muñoz y Monsalve, 2020). En el mismo orden de ideas, los autores mencionan que el aislamiento social durante la pandemia por COVID-19 incluye el confinamiento en casa, que redunda en incremento de la inactividad física y de comportamientos sedentarios, favoreciendo el desacondicionamiento físico, ya que las personas desacondicionadas físicamente tienen alteraciones metabólicas y sistémicas por la falta de movimiento.

Con base en lo anterior, se considera una estrategia preventiva y altamente efectiva para la empresa, el crear programas donde se incluya la actividad física para lograr calidad de vida durante el teletrabajo. Basado en lo anterior, el objetivo de este proyecto de investigación es describir las afectaciones derivadas del trabajo reorganizado a partir del COVID-19, sobre la calidad de vida laboral percibida por un grupo de dueños o gerentes de Pymes y, determinar como influye la actividad fisica para mejorar la salud psicológica que ayude en el rendimiento del trabajador durante la pandemia. 


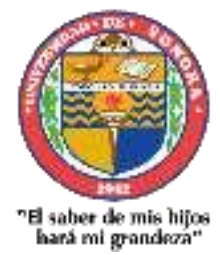

Año 13.

Núm. 33
Revista de Investigación Académica sin Frontera ISSN: 2007-8870 https://revistainvestigacionacademicasinfrontera.unison.mx/index.php/RDIASF

Recibido el 3 de julio de 2020. Dictaminado mediante arbitraje favorablemente 9 de noviembre de 2020.

\section{Materiales y Método}

En este documento se presentan los resultados de una investigación de campo bajo un enfoque metodológico de tipo descriptiva y exploratoria. Su objetivo es describir las afectaciones derivadas del trabajo reorganizado a partir del COVID-19, sobre la calidad de vida laboral percibida por un grupo de trabajadores de Pymes y, determinar como influye la actividad fisica para mejorar la salud psicológica que ayude en el rendimiento del trabajador durante la pandemia. La población de estudio seleccionada para esta investigación fueron trabajadores de 50 empresas Pymes, mismas que se eligieron bajo el criterio de estratificación de las empresas utilizado por el Instituto Nacional de Estadísiticas y Geografía (INEGI) para los censos económicos 2018 de México que fueron obtenidas en marzo del 2020 y acordados por los integrantes de la investigación, al cual se le anexarán otros criterios tales como: sector comercio minorista, con una antigüedad mínima de más de cinco años en el mercado, ubicadas en la ciudad de Hermosillo, Sonora, México, que estuvieron en confinamiento desde 20 de marzo a Junio de 2020 a raíz de la pandemia provocada por el COVID-19. Para este estudio se aplicó un cuestionario estandarizado (validado a juicio de expertos y con un coeficiente de confiabilidad Alpha de Cronbach de 0,92 Muy Alta) por (González-Díaz y Perez, 2015), donde se analizan dos variables: Variable 1; Calidad de vida laboral durante el Teletrabajo a partir del COVID-19 y Variable 2; Actividad Física y Salud. Posteriormente e aplicó a trabajadores de Pymes que estuvieran en confinamiento, ubicadas en la ciudad de Hermosillo, Sonora pertenecientes al sector comercio minorista, con una antigüedad mínima de más de cinco años de actividad en el mercado mediante un Google form (González-Díaz et al., 2016).

\section{Resultados}

Se presentan a continuación los resultados más relevantes de los avances de la investigación basados en el objetivo central de esta investigación. 
Núm. 33

ISSN: 2007-8870

https://revistainvestigacionacademicasinfrontera.unison.mx/index.php/RDIASF

Recibido el 3 de julio de 2020. Dictaminado mediante arbitraje favorablemente 9 de noviembre de 2020.

\subsection{Tabulación, gráficas, interpretación y discusión de los resultados}

\subsubsection{Variable 1; Calidad de vida laboral durante el Teletrabajo a partir del COVID-19}

Imagen 1; Tiempo de confinamiento a partir del COVID-19

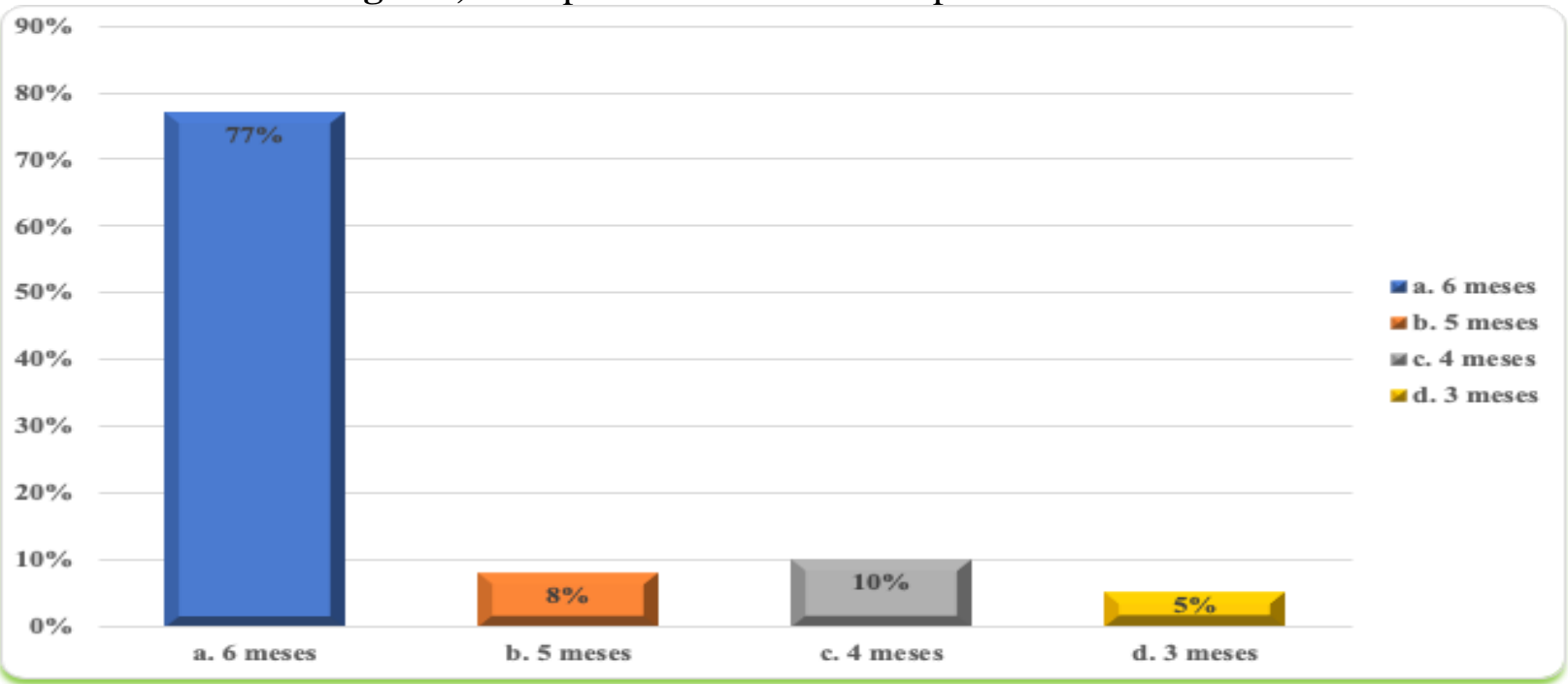

Fuente: Elaboración propia con base a los resultados estadísticos.

En la Imagen 1, se muestra el tiempo de confinamiento a partir del COVID-19 y se observa que del 77\% de las personas de la muestra analizada tienen 6 meses de confinamiento, un 10\% tiene 4 meses, un $8 \% 5$ meses y un $5 \%$ cuenta con 3 meses de confinamiento. 
Núm. 33 ISSN: $2007-8870$ https://revistainvestigacionacademicasinfrontera.unison.mx/index.php/RDIASF

Recibido el 3 de julio de 2020. Dictaminado mediante arbitraje favorablemente 9 de noviembre de 2020.

Imagen 2; Ha trabajado en modalidad de Teletrabajo antes de la pandemia COVID-19

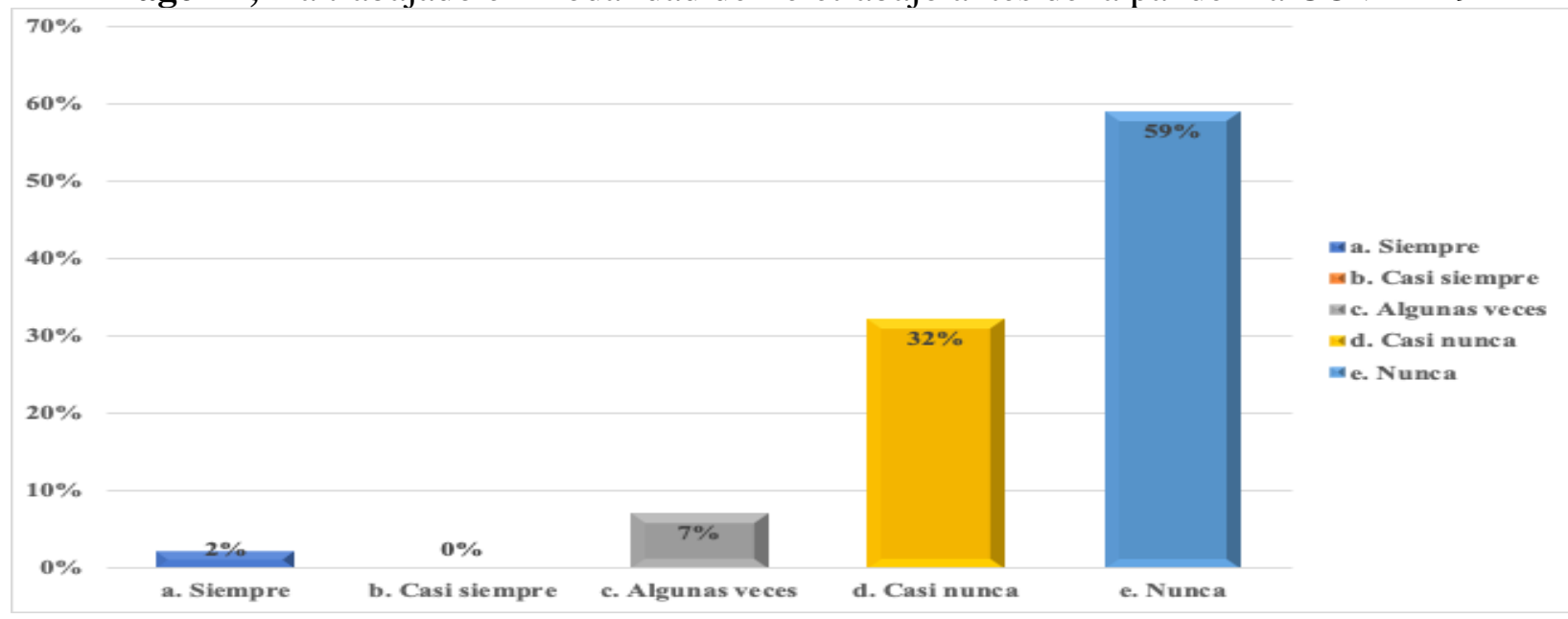

Fuente: Elaboración propia con base a los resultados estadísticos.

En la Imagen 2, se puede observar que el 59\% nunca han trabajado en modalidad de teletrabajo antes de la pandemia COVID-19, el 32\% casi nunca lo ha hecho, un $7 \%$ algunas veces y solo el $2 \%$ menciona que siempre lo ha hecho

Imagen 3; Obtuvo de la empresa una capacitación tecnica para espacios virtuales

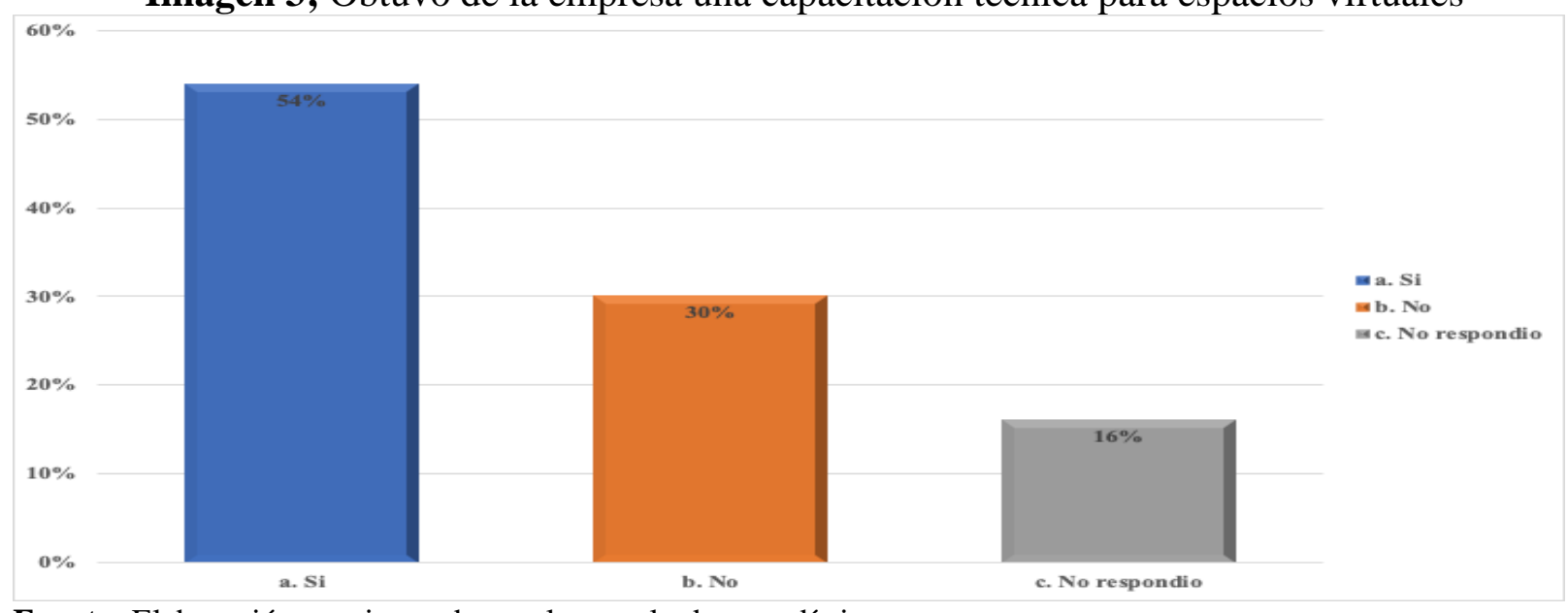

Fuente: Elaboración propia con base a los resultados estadísticos. 


\section{https://revistainvestigacionacademicasinfrontera.unison.mx/index.php/RDIASF}

Recibido el 3 de julio de 2020. Dictaminado mediante arbitraje favorablemente 9 de noviembre de 2020.

En la Imagen 3, se muestra las percepciones de los trabajadores con el fin de indagar sobre aspectos de preparación y necesidades o potencialización en relación a la preocupación de la empresa en ofrecer una capacitación técnica para espacios virtuales. Las respuestas muestran que el 54\% de los trabajadores de la muestra analizada mencionan que si obtuvieron capacitación, el $30 \%$ menciona que no y un $16 \%$ no respondió.

Imagen 4; Adaptación para trabajo en espacios virtuales para enfrentar la crisis

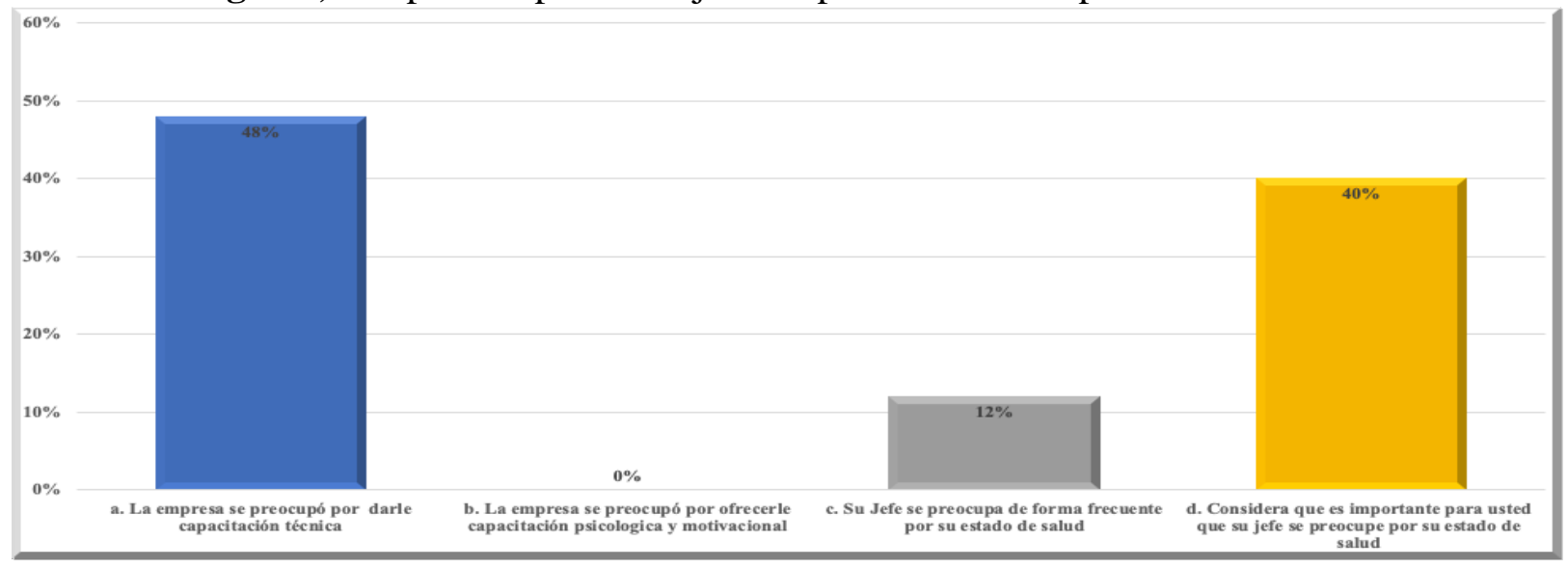

Fuente: Elaboración propia con base a los resultados estadísticos.

En la Imagen 4, se muestra la percepción de los trabajadores en referencia a la adaptación para trabajo en espacios virtuales para enfrentar la crisis y, el $48 \%$ opina que la empresa se preocupó por darle capacitación técnica, el $40 \%$ considera que es importante que su jefe se preocupe por su estado de salud y el $12 \%$ opina que su jefe se preocupa de forma frecuente por su estado de salud. 


\section{https://revistainvestigacionacademicasinfrontera.unison.mx/index.php/RDIASF}

Recibido el 3 de julio de 2020. Dictaminado mediante arbitraje favorablemente 9 de noviembre de 2020.

Imagen 5. Medios con los que cuenta el lugar donde realiza el teletrabajo

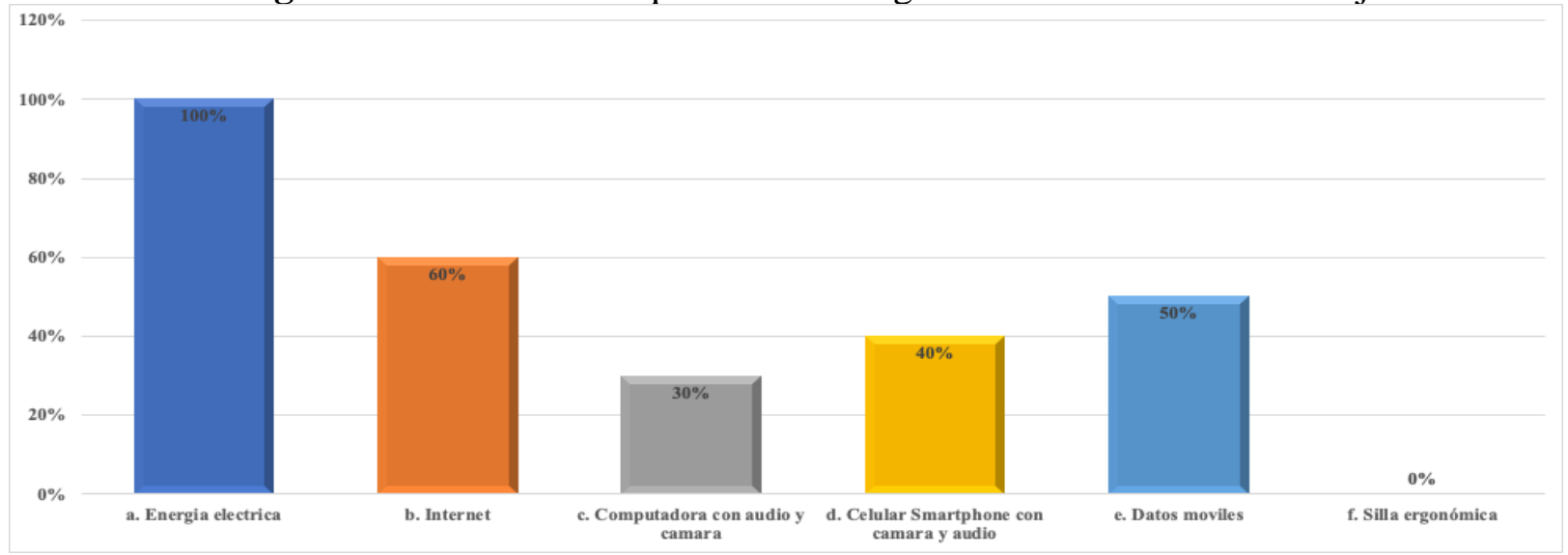

Fuente: Elaboración propia con base a los resultados estadísticos.

En la Imagen 5, se busca conocer sobre aspectos relacionados con el desempeño del colaborador, su lugar de trabajo, independientemente de sus habilidades, por lo tanto, se trata de conocer los medios con los que cuenta el lugar donde realiza el teletrabajo. El 100\% cuenta con energía electrica, el 60\% cuenta con internet, el 30\% con una computadora con cámara y audio, el 50\% con datos moviles, el $40 \%$ cuenta con un celular Smartphone con cámara y audio, pero ninguno cuenta con silla ergonómica.

Imagen 6; Aspectos que el trabajador considera importante durante el teletrabajo

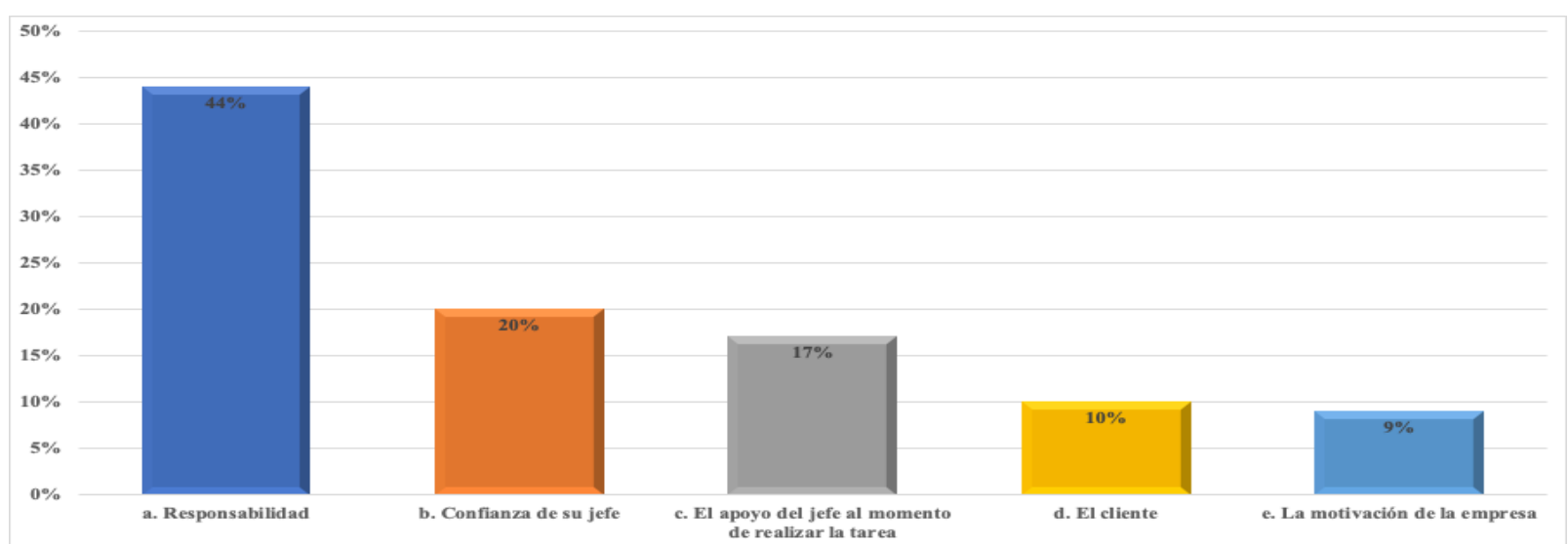

Fuente: Elaboración propia con base a los resultados estadísticos. 
Recibido el 3 de julio de 2020. Dictaminado mediante arbitraje favorablemente 9 de noviembre de 2020.

En la Imagen 6, se analizan los aspectos que el trabajador considera importantes dentro del teletrabajo que realiza. Para el $44 \%$ la responsabilidad es lo más importante, el 20\% menciona la confianza de su jefe, para el 17\% el apoyo del jefe al momento de realizar la tarea, para el 10\% el cliente y el 9\% menciona que lo mas importante es la motivación de la empresa.

Imagen 7. Aspectos que influyen de forma negativa en su desempeño
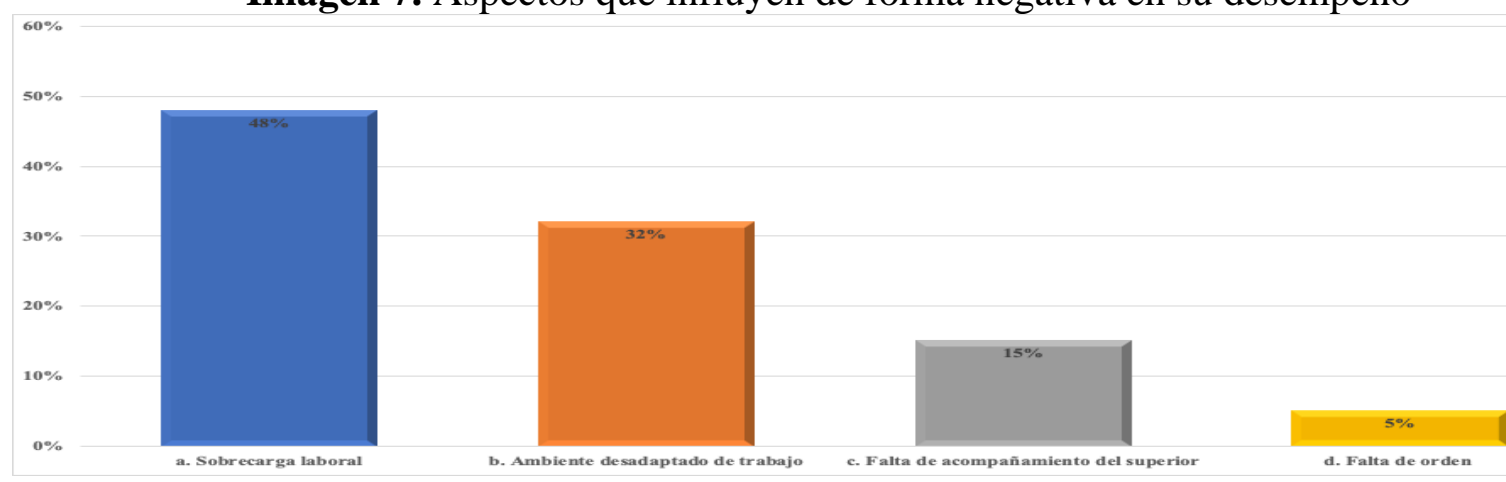

Fuente: Elaboración propia con base en los resultados obtenidos.

En la Imagen 7, se analizan los aspectos que influyen de forma negativa en su desempeño durante el confinamiento. El $48 \%$ menciona que es la sobrecarga laboral es el principal aspecto que influye de manera negativa en su desempeo, donde las personas expresan que por estar en su casa, sus suporiores no ponen límites de tareas y horarios, para el 32\% el ambiente desadaptado de su trabajo ya que en el hogar es donde se realiza esto y allí se convive con eventos externos que irrumpen la atención, o las condiciones propias como implementos, etc., para el 15\% la falta de acompañamiento del superior y el $5 \%$ menciona que es la falta de orden. 


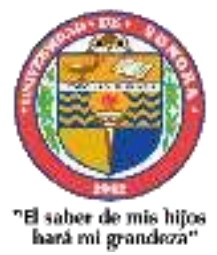

Año 13.

Núm. 33

Revista de Investigación Académica sin Frontera ISSN: 2007-8870 https://revistainvestigacionacademicasinfrontera.unison.mx/index.php/RDIASF

Recibido el 3 de julio de 2020. Dictaminado mediante arbitraje favorablemente 9 de noviembre de 2020.

\subsubsection{Variable 2; Actividad Física y Salud Laboral}

Imagen 8. Realiza actividades físicas antes del confinamiento

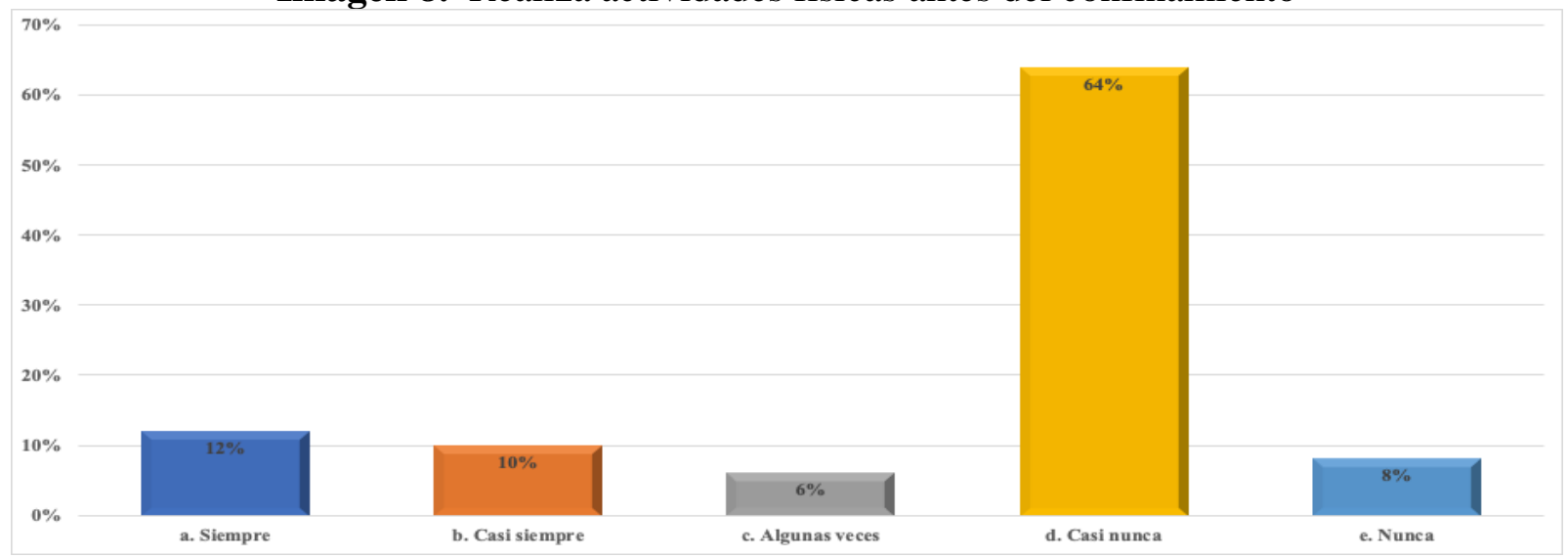

Fuente: Elaboración propia con base en los resultados obtenidos.

En la Imagen 8, se analizan los aspectos relacionados con los hábitos en actividades físicas antes del confinamiento provocado por el COVID-19. El 64\% casi nunca realiza actividad física, el $12 \%$ siempre realiza actividad física, el $10 \%$ casi siempre lo realiza, el $8 \%$ nunca lo hace y el $6 \%$ algunas veces. 


\section{https://revistainvestigacionacademicasinfrontera.unison.mx/index.php/RDIASF}

Recibido el 3 de julio de 2020. Dictaminado mediante arbitraje favorablemente 9 de noviembre de 2020.

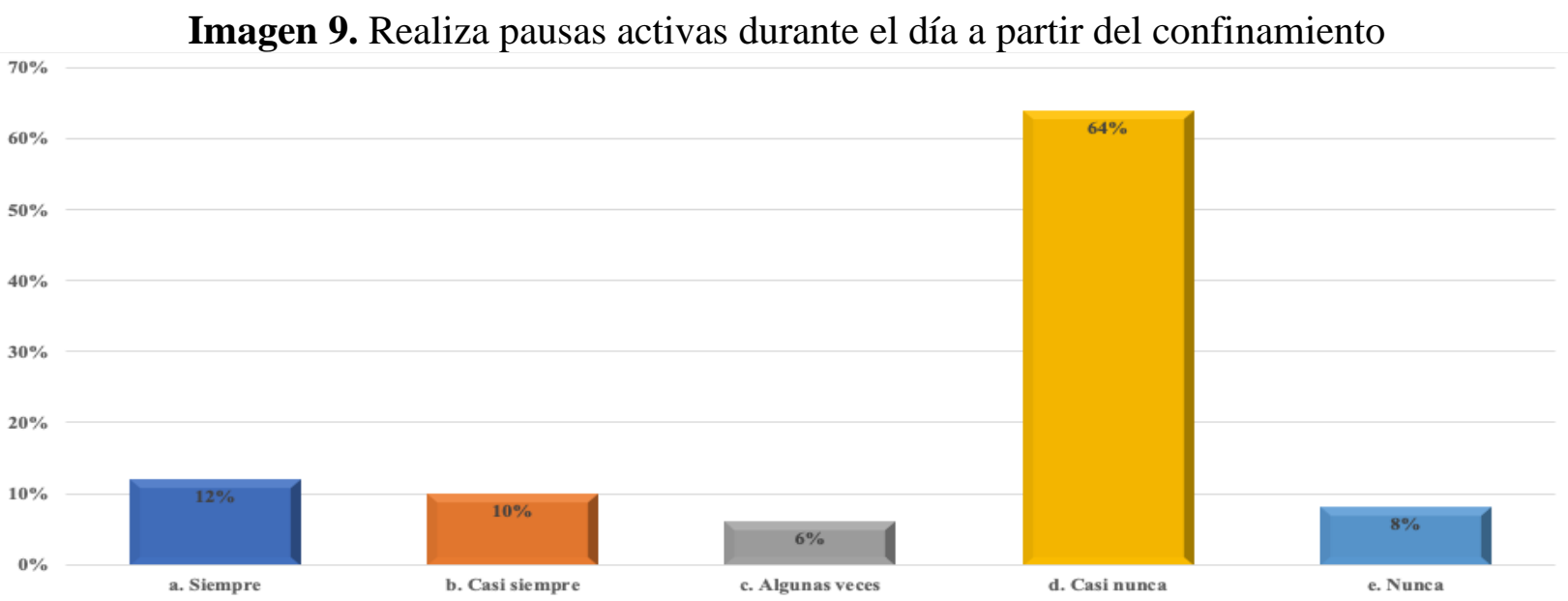

Fuente: Elaboración propia con base en los resultados obtenidos.

La Imagen 9; se pretende conocer si el trabajador realiza pausas activas durante el día a partir del confinamiento provocado por el COVID-19. El 42\% casi nunca las realiza, el $25 \%$ nunca las realiza, el 18\% algunas veces las realiza, el 10\% casi siempre y el 5\% siempre.

Imagen 10. Actividad física y estilo de vida saludable durante el confinamiento

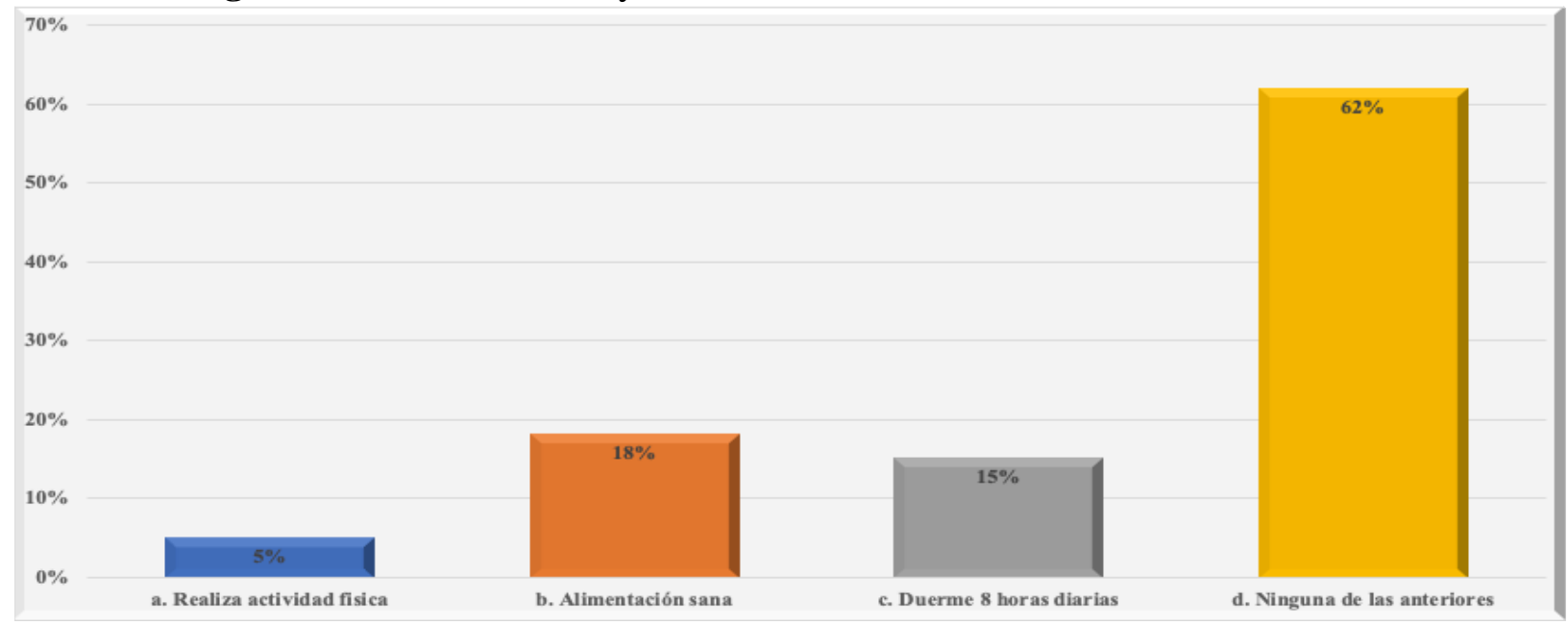

Fuente: Elaboración propia con base en los resultados obtenidos. 


\section{https://revistainvestigacionacademicasinfrontera.unison.mx/index.php/RDIASF}

Recibido el 3 de julio de 2020. Dictaminado mediante arbitraje favorablemente 9 de noviembre de 2020.

La Imagen 10, muestra información relacionada con la actividad física y el estilo de vida saludable del trabajador durante el confinamiento a partir del COVID-19. El 62\% de los trabajadores de la muestra analizada no realiza actividad fisica, no lleva una alimentación sana ni duerme 8 horas diarias, el 18\% lleva una alimentación sana, el 15\% duerme 8 horas diarias y el 5\% realiza actividad física.

Imagen 11. Tiempo invertido en el teletrabajo de forma diaria

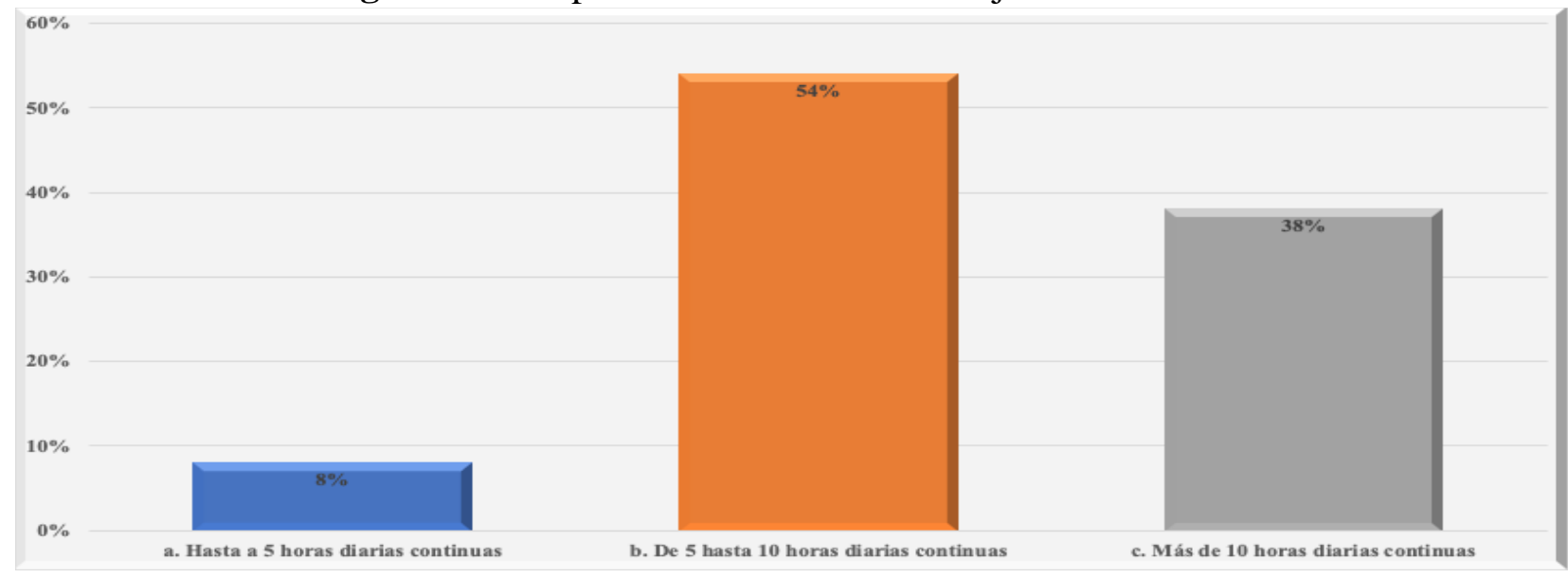

Fuente: Elaboración propia con base en los resultados obtenidos.

En la Imagen 11, muestra información relacionada con el tiempo invertido en el teletrabajo de forma diaria por parte del trabajador. El 54\% le invierte de 5 hasta 10 horas diarias continuas, el $38 \%$ le invierte mas de 10 horas diarias continuas y el $8 \%$ le invierte hasta 5 horas diarias continuas. 
Núm. 33 ISSN: 2007-8870

\section{https://revistainvestigacionacademicasinfrontera.unison.mx/index.php/RDIASF}

Recibido el 3 de julio de 2020. Dictaminado mediante arbitraje favorablemente 9 de noviembre de 2020.

Imagen 12. Espacios de convivencia social y familiar durante la pandemia COVID-19

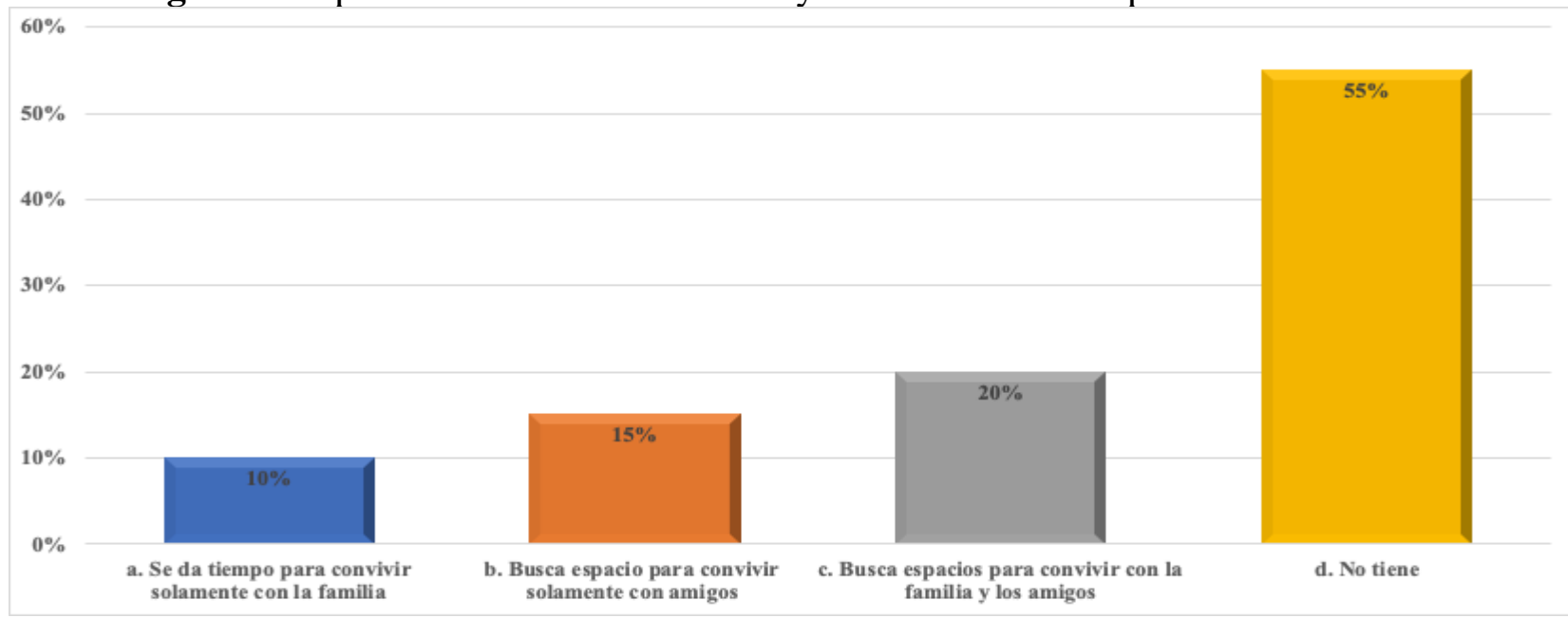

Fuente: Elaboración propia con base en los resultados obtenidos.

En la Imagen 12, se relaciona con los espacios de convivencia social y familiar durante la pandemia COVID-19. El 55\% no los tiene, el $20 \%$ busca espacios para convivencia con la familia y los amigos, el $15 \%$ busca espacios de conviviencia solo con amigos y el $10 \%$ se da tiempo para convivir solo con la familia.

Imagen 13. Principal preocupación durante el confinamiento a partir del COVID-19

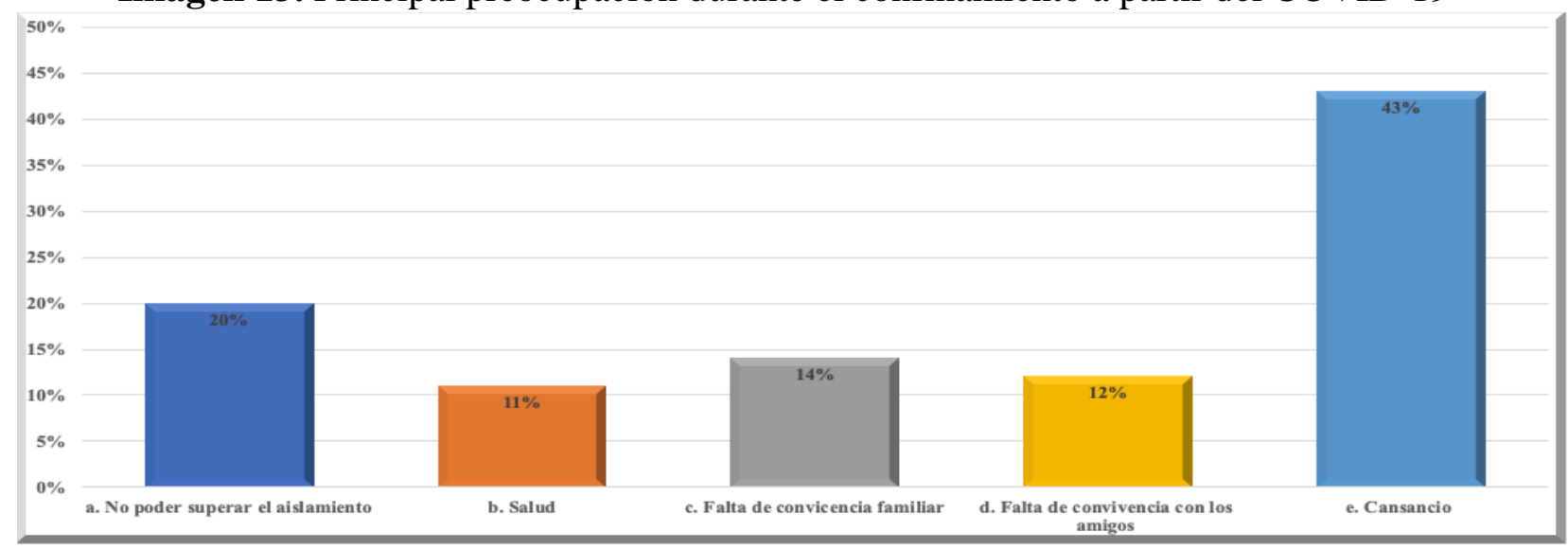

Fuente: Elaboración propia con base en los resultados obtenidos. 
Recibido el 3 de julio de 2020. Dictaminado mediante arbitraje favorablemente 9 de noviembre de 2020.

En la Imagen 13, se relaciona con la principal preocupación durante el confinamiento a partir del COVID-19. Para el $43 \%$ su principal preocupación es el cansancio, para el $20 \%$ su principal preocupación es no superar el aislamiento, para el 14\% es la falta de convivencia familiar, para el $12 \%$ es la falta de convivencia con los amigos y para el $11 \%$ su salud.

\section{Discusión de resultados}

Dentro de los resultados obtenidos se muestra que dentro de la Variable 1; Calidad de vida laboral durante el Teletrabajo a partir del COVID-19, el total de la muestra analizada tiene más de tres meses de confinamiento y más del $90 \%$ nunca había trabajado en modalidad de teletrabajo. Los resultados muestran que cumplir con el objetivo de sus actividades es lo mas importante y que el apoyo del jefe es escencial para lograr su actividad laboral de forma eficiente. Sin embargo, los resultados hacen ver que no ha sido facil para el trabajador y se siente sobrecargado porque no ha sido preparado para enfrentar su nueva modalidad, no todas las empresas se preocupan por dar capacitación técnica para hacer su trabajo y estan conscientes de que en sus casas no cuentan con los medios ni las condiciones necesarios para realizar el teletrabajo y tampoco sus jefes se preocupan por ellos, ni buscan un acercamiento que les haga sentir tomados generando con esto un estrés laboral continuo. Lo anterior permite suponer la importancia de la capacitación y la posibilidad de ver la actividad fisica como una un medio para ayudar al trabajador a superar sus emociones y mejorar su calidad de vida.

Dentro de los resultados de la Variable 2; Actividad Física y Salud Laboral, los resultados muestran que el trabajador invierte muchas horas de trabajo continua y no tiene habitos de actividad física ni antes, ni durante el confinamiento, no lleva un estilo de vida saludable y no le da importancia a los espacios de convivencia y esparcimiento con la familia o los amigos. Para el trabajador es muy importante cumplir con sus obligaciones laborales, pero tantas horas de trabajo continuas bajo la nueva normalidad le ha provocado un cansancio que le preocupa, lo anterior hace suponer que 
https://revistainvestigacionacademicasinfrontera.unison.mx/index.php/RDIASF

Recibido el 3 de julio de 2020. Dictaminado mediante arbitraje favorablemente 9 de noviembre de 2020. posiblemente la falta de actividad fisica, el estilo de vida y los malos hábitos alimeticios le genera con mayor facilidad cansancio, estrés y problemas de salud. En las mismas opiniones mencionan que la empresa no se preocupa por el clima laboral en especial la salud de sus trabajadores, donde posiblemente se pudiera implementar un programa de actividad física y deporte con el fin de incidir en el mantenimiento y la mejora de la salud de sus trabajadores, dando como resultado la mejora de la calidad de vida.

\section{Conclusiones}

El prolongado aislamiento provocado por la pandemia por COVID-19, ha modificado rápidamente el modo de vida de los mexicanos, y la ausencia de una vacuna y tratamiento a corto plazo, exhortan la necesidad del Gobierno de México a emplear estrategias púplicas dirigidas a reducir las tazas de contactos en la población con la idea de reducir la transmisión del virus. Lo anterior, lleva a las empresas a adoptar como medida obligatoria, el enviar a sus trabajadores a realizar el confinamiento en casa. Sin embargo, esta medida implica otros riesgos para la salud del trabajador, tales como los mentales (estrés, ansiedad, alteraciones de sueño), y físicos; el desacondicionamiento físico, dado entre otros, por el incremento de los tiempos de inactividad física, las conductas sedentarias y en muchos casos hasta la mala alimentació.

El confinamiento supone que el trabajador realiza un menor esfuerzo físico en los puestos de trabajo a favor del sedentarismo y, esto aunado a la falta de ejercicio físico en el entorno personal del trabajador ha favorecido el incremento de problemas de salud que lo llevan a tener una baja calidad de vida generando un bajo rendimiento y productividad. Los resultados aquí presentados, hacer ver las afectaciones derivadas del trabajo reorganizado a partir del COVID-19, sobre la calidad de vida laboral y la influencia de la actividad fisica como herramienta para la mejora de la salud psicológica del trabajador que ayude en el rendimiento del trabajador en actividades de teletrabajo (Xiang et al., 2020). 


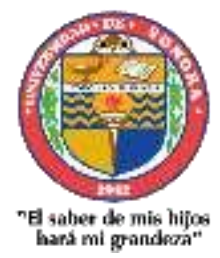

Año 13.

Núm. 33
Revista de Investigación Académica sin Frontera ISSN: 2007-8870 https://revistainvestigacionacademicasinfrontera.unison.mx/index.php/RDIASF

Recibido el 3 de julio de 2020. Dictaminado mediante arbitraje favorablemente 9 de noviembre de 2020.

Si bien es cierto, la evidencia empírica hasta este momento aun es escasa, y no podemos afirmar que la Actividad Física podría disminuir los riesgos de infección por COVID-19, hay suficiente evidencia que demuestra que la Actividad Física planificada, estructurada, repetitiva y realizada por medio de pausaas activas tiene una relación con la mejora o el mantenimiento de uno o más de los componentes de la aptitud física, porque al realizarla de forma continua protege la salud del individuo, y se ha documentado la ayuda que brinda al control del estrés porque ayuda a mantener la función inmune, particularmente en personas sometidas a periodos largos de aislamiento y confinamiento como los presentados por la pandemia actual (Simpson, 2020) .

A modo de conclusión final y tomando en cuenta los planteamientos anteriores, se hace ver que al momento de realizar un confinamiento de un trabajador que por ende provoca un desacondicionamiento físico, asociado a un aislamiento social, es importante que la empresa pueda incorporar un programa que contenga estrategias relacionadas con la Actividad Fisica, así como algunas recomendaciones de alimentación y medidas de pausas activas sumadas al descanso adecuado que ayuden a disminuir el estrés y la ansiedad mediante actividades virtuales que ayuden en el mantenimiento de la condición física, y su efectividad implica que se involucren dentro de un plan estructurado que permita el desarrollo de diferentes actividades, dentro de horarios determinados, incluso incluyendo a la familia y acorde a la capacidad de cada individuo. Esto, puede traer beneficios inmediatos en la reducción del riesgo de infección y mejorar la calidad de vida en familia, y otros en el mediano y largo plazo, como constituir un estilo de vida saludable como elemento protector de enfermedades crónicas e infecciosas.

Este estudio presenta varias limitaciones que sugieren vías de investigación futuras. La percepción del la Calidad de Vida Laboral de empresas de mediano y mayor tamaño, es un resultado que debe 


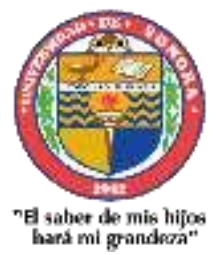

Año 13.

Núm. 33
Revista de Investigación Académica sin Frontera ISSN: 2007-8870

https://revistainvestigacionacademicasinfrontera.unison.mx/index.php/RDIASF

Recibido el 3 de julio de 2020. Dictaminado mediante arbitraje favorablemente 9 de noviembre de 2020. analizarse para descartar la relatividad a su tamaño y éxito empresarial basado en su giro. Posteriormente, sería interesante profundizar en los efectos de la correlación entre otras variables que ayude en las estrategias gestión empresarial para la mejora del trabajo que se realiza en materia de rentabilidad y productividad que le permitan lograr ventaja competitiva a la empresa. Los resultados aquí presentados comprueban el objetivo planteado en la investigación donde se destaca la importancia de que las Pymes desarrollen e implementen un programa de ejercicio físico sistematizado y controlado en la empresa, con el propósito de mejorar la salud y calidad de vida del trabajador que ayude a desarrollar un rendimiento. 
https://revistainvestigacionacademicasinfrontera.unison.mx/index.php/RDIASF

Recibido el 3 de julio de 2020. Dictaminado mediante arbitraje favorablemente 9 de noviembre de 2020.

\section{Referencias}

Chen, P., Mao, L., Nassis, G.P., Harmer, P., Ainsworth, B.E. y Li, F. (2020). Coronavirus disease (COVID-19): The need to maintain regular physical activity while taking precautions. J Sport Health Sci; 9(2):103-1044. https://doi.org/10.1016/j.jshs.2020.02.001

Culma, B., Londoño, D., García, y Tabares, D. (2020). La Cultura y el Clima de las Organizaciones en Época del Confinamiento a Causa del Covid-19. CIE. Vol. 1. (9), 45-56.

De Miguel Calvo, J. M.; Schweiger Gallo, I.; de las Mozas Majano, O.; Hernández López, J. M. (2011). Efecto del ejercicio físico en la productividad laboral y el bienestar Revista de Psicología del Deporte, 20(2), 589-604.

Díaz, R. R. G., y Ramos, D. E. C. (2019). Crecimiento financiero en las entidades del sector cooperativo a través de la bolsa de valores de Colombia. Centros: Revista Científica Universitaria, 8(1), 127-143.

Gené Badia, J., Ruiz Sánchez, M., Obiols Masó, N., Oliveras Puig, L. y Lagarda Jiménez, E. (2016). Aislamiento social y soledad: ¿qué podemos hacer los equipos de atención primaria? Aten Primaria 48(9):604-649.

González-Díaz, R. R., y Perez, L. A. B. (2015). Análisis financiero empresarial del sector comercio como factor de competitividad través de la lógica difusa. Estrategia, 1(1), 110 .

González-Díaz, R. R., Lara, R. J. V., López, R. O., y Hernández Royett, J. (2016). Tax on advertising and commercial advertising: An analysis from Municipal Tax Management. Globalciencia, 2(1), 20-34.

Grote, G. y Guest, D. (2017). The case for reinvigorating quality of working life research. Human Relations, 70(2), 149-167.

Lee I-M, Shiroma EJ, Lobelo F, Puska P, Blair SN, Katzmarzyk PT, et al. (2012). Effect of physical inactivity on major non-communicable diseases worldwide: an analysis of burden of disease 
Recibido el 3 de julio de 2020. Dictaminado mediante arbitraje favorablemente 9 de noviembre de 2020. and life expectancy. Lancet, 380(9838):219-229. Disponible en: https://www.thelancet.com/journals/lancet/article/PIIS0140-6736(12)61031-9/fulltext

Mencías, J.X., Ortega, D. M., Zuleta, C.W., Calero, S. (2016). Mejoramiento del estado de ánimo del adulto mayor a través de actividades recreativas. Lecturas: Educación Física y Deportes. 20(212), 1-13.

Mera, A., Tabares Gonzalez, E., Montoya Gonzalez, S., Muñoz Rodriguez, D., y Monsalve Vélez, F. (2020). Recomendaciones prácticas para evitar el desacondicionamiento físico durante el confinamiento por pandemia asociada a COVID-19. Universidad Y Salud, 22(2), 166177.

Meza Barajas, E. (2017). Análisis en la percepción del género entre clima organizacional y satisfacción laboral del sector industrial - México. COMUNI@CCION: Revista de Investigación en Comunicación y Desarrollo, 8 (2), 148-158

Montero, L. F, Chávez, E. (2015). Disminución del sedentarismo en adolescentes del colegio Atahualpa, Cantón Machala, a través de un programa de recreación físico-deportivo. Lecturas: Educación Física y Deportes. 2015; 20(210), 1-13.

Morales, S., Díaz, T., Cumbajin, M.R., Torres, Á.F. y Analuiza, E.F. (2016). Influencia de las actividades físico-recreativas en la autoestima del adulto mayor. Revista Cubana de Investigaciones Biomédicas.;35(4); 366-374.

Morales, S., Velasco, I.M., Lorenzo, A., Torres, Á.F., Enríquez, N.R. (2016). Actividades físicorecreativas para disminuir la obesidad en mujeres entre los 35-50 años de edad. Revista Cubana de Investigaciones Biomédicas. 35(4): 0-0.

Organización Internacional del Trabajo (2020). Frente a la pandemia: Garantizar la seguridad y salud en el trabajo. Primera edición, Ginebra: OIT, 2020. https://www.ilo.org/wcmsp5/groups/public/---ed_protect/---protrav/--safework/documents/publication/wcms 742732.pdf 
https://revistainvestigacionacademicasinfrontera.unison.mx/index.php/RDIASF

Recibido el 3 de julio de 2020. Dictaminado mediante arbitraje favorablemente 9 de noviembre de 2020.

Organización Internacional del Trabajo. (2017). Centro Interamericano para el Desarrollo del Conocimiento en la Formación Profesional- CINTERFOR. Definición de Teletrabajo. Obtenido de Organización Internacional del Trabajo Disponible en: http://www.oitcinterfor.org/?q=taxonomy/term/3454

Saco Barrios, R. (2007). El Teletrabajo. Revista Derecho PUCP- Pontificia Universidad Católica del Perú No. 60.

Sánchez Castañeda, A. y Hernández Ramírez, J.P. (2020). La respuesta del gobierno de México ante el COVID-19. Cielo Laboral, 1-6.

Sandoval, M.L., Burbano, D. (2015). Actividades recreativas acuáticas en el desarrollo psicomotriz en niños de 6 a 15 años con parálisis cerebral leve, moderada. Lecturas: Educación Física y Deportes. 20(210); 1-9.

Sandoval, M.L., Marcel, T., Carrasco, O.R. (2015). Incidencia de las actividades físico-recreativas, en la condición física de mujeres aspirantes a policías de la provincia de Pichincha. Lecturas: Educación Física y Deportes. 20(210); 1-11.

Simpson, R. J. (2020). American Collegue of sports medicine ACSM's. Ejercicio, inmunidad y la pandemia del COVID-19. Disponible en: https://www.acsm.org/blog-detail/acsmblog/2020/04/16/ejercicio-inmunidad-y-la-pandemia-del-covid-19

Sobrado Olalde, I. (2008). La educación física de los estudiantes de la Universidad de las ciencias informáticas. Odiseo Revista Electrónica de pedagogía. https://odiseo.com.mx/bitacoraeducativa/la-educacion-fisica-en-los-estudiantes-de-la-universidad-de-las-cienciasinformaticas/

Xiang YT, Yang Y, Li W, Zhang L, Zhang Q, Cheung T, et al. (2020). Timely mental health care for the 2019 novel coronavirus outbreak is urgently needed. Lancet Psychiatry;7(3), 2289. 
Núm. 33

ISSN: 2007-8870

https://revistainvestigacionacademicasinfrontera.unison.mx/index.php/RDIASF

Recibido el 3 de julio de 2020. Dictaminado mediante arbitraje favorablemente 9 de noviembre de 2020.

\section{Directorio Institucional}

\section{Dr. Enrique Fernando Velázquez Contreras \\ Rector}

Dr. Ramón Enrique Robles Zepeda

Secretario General Académico

Dra. Rosa María Montesinos Cisneros

Secretaria General Administrativa

Dr. Rodolfo Basurto Álvarez

Director de Vinculación y Difusión

Dra. Adriana Leticia Navarro Verdugo

Vicerrectora de la Unidad Regional Sur

Dr. Ernesto Clark Valenzuela

Director de la División de Ciencias Económicas y Sociales

Dr. Francisco Espinoza Morales

Secretario de la División de Ciencias Económico y Sociales

Dra. Leticia María González Velásquez

Jefe del Departamento de Ciencias Económico Administrativas

Dra. Lidia Amalia Zallas Esquer

Jefe de Departamento de Ciencias Sociales 
Núm. 33 ISSN: 2007-8870

https://revistainvestigacionacademicasinfrontera.unison.mx/index.php/RDIASF

Recibido el 3 de julio de 2020. Dictaminado mediante arbitraje favorablemente 9 de noviembre de 2020.

\section{Comité Directivo}

\section{Editor Responsable}

Dr. Francisco Espinoza Morales

\section{Directora}

Dra. Leticia María González Velásquez

\section{Subdirector}

Dr. Javier Carreón Guillen

\section{Editor Científico}

Dr. Cruz García Lirios

\section{Master Gráfico}

M.T.I. Francisco Alan Espinoza Zallas 
Núm. 33 ISSN: 2007-8870

https://revistainvestigacionacademicasinfrontera.unison.mx/index.php/RDIASF

Recibido el 3 de julio de 2020. Dictaminado mediante arbitraje favorablemente 9 de noviembre de 2020.

\section{Comité editorial}

Dra. Angélica María Rascón Larios

Universidad de Sonora. México

Dra. María del Rosario Molina González

Universidad de Sonora

Dra. Francisca Elena Rochin Wong

Universidad de Sonora. México

Dra. Lidia Amalia Zallas Esquer

Universidad de Sonora. México

Dra. Beatriz Llamas Arechiga

Universidad de Sonora. México

Dr. Rogelio Barba Álvarez

Universidad de Guadalajara. México

Dra. Rosa María Rincón Ornelas

Universidad de Sonora. México

Dr. Juan Flores Preciado

Universidad de Colima. México

Dr. Amado Olivares Leal.

Universidad de Sonora. México

Dr. Guillermo Velásquez Valadez.

Instituto Politécnico Nacional (IPN) México

Dr. Hugo Nefstalí Padilla Torres.

Universidad Estatal de Sonora. México

MSc. Celso Germán Sánchez Zayas

Universidad de Camagüey, Ignacio Agramonte Loynaz, Cuba 


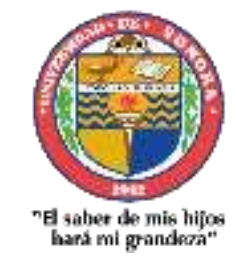

Año 13.

Núm. 33
Revista de Investigación Académica sin Frontera

ISSN: 2007-8870

https://revistainvestigacionacademicasinfrontera.unison.mx/index.php/RDIASF

Recibido el 3 de julio de 2020. Dictaminado mediante arbitraje favorablemente 9 de noviembre de 2020.

Dr. Luis Ramón Moreno Moreno.

Universidad Autónoma de Baja California. México

Dr. Miguel Ángel Vázquez Ruiz.

Universidad de Sonora. México

Dra. Lorena Vélez García.

Universidad Autónoma de Baja California. México

Dra. Pabla Peralta Miranda.

Universidad Simón Bolívar, Barranquilla, Colombia

Mtro. Roberto Espíritu Olmos.

Universidad de Colima (FCA Tecomán) Colima

Dr. Héctor Priego Huertas.

Universidad de Colima (FCA Tecomán) Colima

Mtra. María Guadalupe Alvarado Ibarra.

Universidad de Sonora. México.

Dra. María Luisa Quintero Soto

Universidad Autónoma del Estado de México

Dr. Eyder Bolivar Mojica

Universidad Católica, Luis Amigó, Medellin, Colombia

Revisores de Textos en Inglés

Mtro. Renato Encinas

Mtra. Cecilia Guadalupe Martinez Solano 
https://revistainvestigacionacademicasinfrontera.unison.mx/index.php/RDIASF

Recibido el 3 de julio de 2020. Dictaminado mediante arbitraje favorablemente 9 de noviembre de 2020.

\section{Comité científico}

Dr. Rosendo Martínez Jiménez. Universidad Autónoma Benito Juárez de Oaxaca.

Dr. Hugo Neftalí Padilla. Universidad Estatal de Sonora

Dra. María Teresa Gaxiola Sánchez. Universidad de Sonora.

Dr. José Cesar Kaplan. Universidad estatal de Sonora.

Dr. Alfredo Islas Rodriguez. Universidad de Sonora

Frecuencia de publicación: semestral / 2 números por año.

Revista de Investigación Académica sin Frontera (RIASF) con (ISSN: 2007-8870) es un interlocutor internacional de acceso abierto revisado diario en línea en el ámbito de las Ciencias Económicas Administrativas y Sociales. Su objetivo principal es dar a los trabajos de investigación de calidad. Cubre todas las sub-campos de los campos anteriormente mencionados. Proporciona la plataforma a académicos, estudiantes y profesionales. Sólo pública trabajos de investigación y artículos de revisión inicial. Documento presentado debe cumplir con algunos criterios como, debe ser original, inédita y no estén sometidos a ninguna otra revista.

RIASF es una revista arbitrada / Revisión por pares International. Publicamos documentos sobre una variedad de temas, contextos y estrategias de análisis que examinan la relación entre la rápida evolución para la Sociedad y la tecnología del conocimiento. 
Núm. 33

ISSN: 2007-8870

https://revistainvestigacionacademicasinfrontera.unison.mx/index.php/RDIASF

Recibido el 3 de julio de 2020. Dictaminado mediante arbitraje favorablemente 9 de noviembre de 2020.

Nos complace anunciar que su diario, "Academic Research Journal Withoutborders" (ISSN/EISSN 2007-8870) fue evaluado positivamente en la indexación Citefactor, ahora la página de la revista está disponible en línea, en caso de cualquier problema. \begin{tabular}{l|l} 
Journals Master & International Innovative Journal Impact Factor \\
$\underline{(I I J I F)}$
\end{tabular}

Red Latinoamericana de revistas Académicas en Ciencias Sociales y Humanidades 